\title{
Effects of bleaching on absorbency and strength of jute-cotton union furnishing fabrics
}

\section{LOPAMUDRA NAYAK}

Received: 22.08.2014; Revised: 13.09.2014; Accepted: 25.09.2014

Author for correspondence: LOPAMUDRA NAYAK Department of Textile and Apparel Designing, Orissa University of Agriculture and Technology, BHUBANESWAR (ODISHA) INDIA

Email: licha.lopa@gmail.com
ABSTRACT : Bleaching of jute-cotton union fabric has been carried out using different chemicals and methods. It was found that the Sample $\mathrm{L}$ bleached with sodium silicate and $\mathrm{H}_{2} \mathrm{O}_{2}$ sequentially at $85^{\circ} \mathrm{C}$ for one hour then at room temperature for another hour and the sample $\mathrm{M}$ bleached at RT with a sequential combination of chemicals produce acceptable level of whiteness and efficient to carry out the colouration process successfully and these processes are energy saving, economical and also minimize damage in fabric strength. The absorbency property of these samples was very satisfactory, hence, efficient to carry out the colouration process successfully besides, these processes are energy saving, economical and also minimize damage to fabric tearing and bursting strengths. Moreover, the increase in absorbency of these materials, particularly for sample $\mathrm{M}$ was at par with conventional kier-boiled and bleached sample $\mathrm{N}$. Conventional bleaching process produces a pure white colour but there was substantial loss in fabric strength and weight.

KEY WORDS: Union fabrics, Pretreatments, Bleaching, Water absorbency, Strength, Colouring

口 HOW TO CITE THIS PAPER : Nayak, Lopamudra (2014). Effects of bleaching on absorbency and strength of jute-cotton union furnishing fabrics. Asian J. Home Sci., 9 (2) : 380-387. 